\title{
Management Of Excessive Sleepiness In Patients With Narcolepsy And OSA: Current Challenges And Future Prospects
}

This article was published in the following Dove Press journal:

Nature and Science of Sleep

\author{
Ashima S Sahni \\ Melissa Carlucci \\ Malik Malik \\ Bharati Prasad \\ Division of Pulmonary, Critical Care, \\ Sleep and Allergy, Department of \\ Medicine, University of Illinois at Chicago, \\ Chicago, IL, USA
}

\begin{abstract}
Excessive daytime sleepiness (EDS) can be caused by insufficient sleep but is also a manifestation of medical or sleep disorders and a side effect of medications. It impacts quality of life and creates safety concerns in the home, at work, and on the roads. Screening questionnaires can be used to estimate EDS, but further evaluation is necessary. EDS is a common symptom of both narcolepsy and obstructive sleep apnea (OSA). Polysomnography and multiple sleep latency testing are used to diagnose these disorders. However, isolating the primary etiology of EDS can be challenging and may be multifactorial. Untreated OSA can show polysomnographic findings that are similar to narcolepsy. The effects of sleep deprivation and certain medications can also affect the polysomnographic results. These challenges can lead to misdiagnosis. In addition, narcolepsy and OSA can occur as comorbid disorders. If EDS persists despite adequate treatment for either disorder, a comorbid diagnosis should be sought. Thus, despite advances in clinical practice, appropriate management of these patients can be challenging. This review is focused on EDS due to OSA and narcolepsy and addresses some of the challenges with managing this patient population.
\end{abstract}

Keywords: EDS, excessive daytime sleepiness, narcolepsy, OSA, obstructive sleep apnea

\section{Introduction}

Excessive daytime sleepiness (EDS) is defined as unintentional sleepiness or inability to maintain wakefulness, thus impacting one's functional ability. ${ }^{1}$ Due to the subjectivity associated with self-reported EDS, prevalence in the general population is difficult to estimate. A recent population-based study showed that $33 \%$ of participants self-reported EDS at baseline and that $28 \%$ of participants without EDS at baseline developed EDS during the 5-year study period. Younger age and depression were independent predictors of incident EDS, and the degree of EDS fluctuated over time. ${ }^{2}$ The term EDS is used interchangeably with hypersomnolence, though EDS is a symptom and hypersomnolence is a disease process.

EDS impacts quality of life and contributes to unsafe work and home environments, in addition to jeopardizing public safety on the roads. ${ }^{3}$ The most common cause of EDS is insufficient sleep syndrome. However, EDS is also a common symptom of medical disorders and a side effect of various prescription and overthe-counter medications. EDS can be a manifestation of sleep disorders, including obstructive sleep apnea (OSA), alveolar hypoventilation, restless leg syndrome, periodic limb movement disorder, circadian rhythm disorder, narcolepsy, idiopathic
Correspondence: Ashima S Sahni Division of Pulmonary, Critical Care, Sleep and Allergy, Department of Medicine, University of Illinois at Chicago (MC 719), 909 South Wolcott Avenue, Room 3135 (MC 719), Chicago, IL 606I2, USA

Tel +I $312355-4806$

Email asahni@uic.edu 
hypersomnia and Kleine-Levin syndrome. Other medical disorders in which EDS is a clinical symptom include hypothyroidism, renal/hepatic failure, neurodegenerative disorders such as Parkinsonism, stroke, myotonic dystrophy, multiple sclerosis, structural brain lesions, traumatic brain injury, and psychiatric disorders such as depression, anxiety, and substance abuse. Medications associated with EDS include sedative-hypnotics, beta blockers, antihistamines, anticonvulsants, antidepressants and opiates. The overlap of multiple risk factors in individual patients can present a diagnostic dilemma. Thus, alternative diagnoses for EDS should be considered if the patient does not respond to the primary management. ${ }^{4}$ Residual sleepiness in adequately treated patients with OSA can be multifactorial and requires further investigation and management. ${ }^{5}$

\section{Epidemiology}

Obstructive sleep apnea is a common disorder in North America. The estimated prevalence in the general adult population has been reported as $9 \%$ to $38 \%{ }^{6}$ The prevalence of narcolepsy is much lower in the general adult population and has been reported as $0.07 \%$ to $0.20 \%{ }^{7}$ The occurrence of OSA in the setting of narcolepsy is at best speculative. In a retrospective study of 133 patients with narcolepsy, $25 \%$ of patients had an apnea hypopnea index $(\mathrm{AHI}) \geq 10$. Thirty percent of patients with $\mathrm{AHI} \geq 10$ were initially diagnosed with OSA only, and there was a delay in the diagnosis of narcolepsy. ${ }^{4}$ Narcolepsy is associated with increased body mass index (BMI), which is a risk factor for OSA, again leading to under-diagnosis of narcolepsy. ${ }^{8}$ Additionally, two or more sleep onset REM periods (SOREMs) may be observed on the multiple sleep onset latency test (MSLT) in patients with untreated OSA, potentially confounding the true prevalence of either disorder. ${ }^{9}$

\section{Pathophysiology Narcolepsy}

Breakthrough in the pathogenesis of narcolepsy occurred in 1998 when two groups of researchers identified the same gene in animal models. Lecea et al. ${ }^{10}$ named this new gene hypocretin and Sakurai et al. ${ }^{11}$ referred to it as orexin. Hypocretin/orexin is a neuropeptide produced in the lateral posterior hypothalamus. It plays a crucial role in control of the sleep/wake cycle and of neurocognitive and metabolic functions. The pathophysiology of type 1 narcolepsy (NT1) is characterized by destruction of hypocretin/ orexin-producing neurons and reduced levels of hypocretin/orexin in the cerebrospinal fluid (CSF). The destruction of these specific neurons is thought to be related to an autoimmune mechanism, though no direct evidence has been found. The arguments that support this theory are linked to a strong association between NT1 and the HLADQB1*0602 allele and polymorphisms. Seasonal variation in the incidence of NT1 suggests infectious etiologies, with an increased incidence of NT1 in Scandinavia after the Pandemrix vaccination for the H1N1 influenza virus was introduced. There is also a suggestion that NT1 is associated with Streptococcus infections with the finding of increased antibody titers to Streptococcus pyogenes when compared to controls. ${ }^{12}$ In contrast to NT1, the pathophysiology of type 2 narcolepsy (NT2) is unknown, though it is thought to be due to less extensive damage to hypocretin/orexin. Most patients with NT2 have normal hypocretin levels; however, NT2 seems to be a heterogeneous disorder and subgroups may exist. ${ }^{1}$

To elaborate on the genetic predisposition to narcolepsy, $86-98 \%$ of patients with NT1 are positive for the HLA-DQB1*0602 allele, though that is not sufficient to develop the disease. This allele is also reported in 5-38\% of the general population. Some studies have reported a higher prevalence of this allele in NT2 than the general population, but the data are limited. ${ }^{13}$

In a small study of 26 patients, increased BMI in patients with narcolepsy/cataplexy was not correlated with their CSF hypocretin levels. This finding suggests that other metabolic mechanisms could explain the association of obesity with narcolepsy. ${ }^{14}$ In another study, higher BMI was associated with delayed diagnosis. ${ }^{15}$ Animal studies support the loss of hypocretin neurons rather than loss of hypocretin itself to be responsible for the weight gain. Some studies indicate that the food choices of patients with NT1 when compared to controls may also contribute to weight gain. This could indicate altered reward motivation and processing in patients with NT1 because binge eating, nocturnal eating, and carbohydrate craving have been reported in NT1. ${ }^{16,17}$

\section{OSA And Excessive Daytime Sleepiness}

Repeated upper airway obstruction leading to arousals and sleep fragmentation is thought to result in EDS in patients with OSA. ${ }^{18}$ Variable results have been found linking intermittent nocturnal hypoxemia as well, but no clear correlation exists between the severity of sleep apnea and degree of EDS. ${ }^{19,20}$ Chronic intermittent nocturnal 
hypoxemia could potentially injure wake-promoting neural networks with loss of dopaminergic and noradrenergic neurons, thus contributing to EDS. These effects were seen as early as two weeks in mice models. ${ }^{21,22}$ A retrospective analysis in which untreated OSA was associated with two SOREMs on the MSLT found baseline minimal oxygen saturation to be an independent predictor, which raises the possibility of nocturnal hypoxemia as a promoter of SOREMs and EDS. ${ }^{23}$ Autonomic dysregulation with increased sympathetic cardiac tone during autonomic arousals in patients with OSA may also contribute to EDS. ${ }^{24,25}$ Additionally, obesity itself could be a contributing factor to EDS in patients with OSA via adipokines and chronic inflammation noted in obese patients. ${ }^{26}$

\section{Diagnosis And Current Diagnostic Challenges}

EDS is the primary clinical symptom associated with narcolepsy. EDS is typically the first symptom to present and often has the greatest impact on daily life. Patients with narcolepsy experience generalized EDS in addition to involuntary lapses into sleep. Daily occurrence of EDS for at least three months is a required criterion for the diagnosis of narcolepsy. ${ }^{1}$ EDS is also a common presenting symptom of OSA, but it does not occur universally and is not a required criterion for diagnosis. ${ }^{1}$ EDS is often confused with fatigue, exhaustion, lethargy, tiredness, and lassitude.

Sleep deprivation is the most common cause of EDS. This could be behaviorally induced or related to circadian misalignment. Medication reconciliation needs to be done to ensure that the patient is not taking sedating medications. Although not an exhaustive list, these may include benzodiazepines, non-benzodiazepines, opiates, antihistamines, anti-epileptics, antidepressants, nonsteroidal antiinflammatory drugs, digoxin, clonidine, prazosin, and beta-blockers. Substance abuse, including alcohol and marijuana, and endocrine disorders (especially hypothyroidism) should also be ruled out. Other pertinent history includes the presence of neurological lesions, stroke, traumatic brain injury, multiple sclerosis, neurodegenerative disorders, encephalopathies and neuromuscular disorders (Parkinson's disease, myotonic dystrophy, amyotrophic lateral sclerosis, myasthenia gravis). In addition, other medical conditions such as heart failure, COPD, and rheumatological conditions should be evaluated. Psychiatric disorders including depression, PTSD, and anxiety need to be evaluated and treated. Other considerations include restless legs syndrome, periodic limb movement disorder of sleep, and parasomnias. A key tool for investigating EDS is an overnight polysomnogram (PSG) followed by a daytime MSLT to evaluate for sleep disorders that have no obvious etiologic basis.

\section{Screening Tools}

The approach to a patient with EDS includes a subjective evaluation of EDS that can be done using a variety of validated scales. The Epworth Sleepiness Scale (ESS) is a self-administered questionnaire in which respondents rate their chances of falling asleep in eight situations that commonly occur in daily life. ${ }^{27}$ Each situation is rated on a scale of $0-3$ based on how likely the respondent is to fall asleep, with a score of greater than 10 being consistent with EDS. ${ }^{28}$ The Epworth Sleepiness Scale for Children and Adolescents (ESS-CHAD) is a version of the ESS that has been modified to reflect the experiences of younger respondents. ${ }^{29}$

Other scales that may be used include the Karolinska Sleepiness Scale (KSS), Stanford Sleepiness Scale (SSS), and Pittsburgh Sleep Quality Index (PSQI). The KSS and SSS are validated measures of subjective sleepiness at a particular time. ${ }^{30,31}$ For the KSS, respondents rate their sleepiness in the preceding five minutes on a 9-point scale, $^{31}$ and for the SSS, respondents rate their current sleepiness on a 7-point scale. ${ }^{30}$ Because the KSS and SSS are both answered at one point in time, they may be useful to assess sleepiness as it relates to different activities, times of day, or levels of sleep. The PSQI is a validated tool that includes an evaluation of daytime dysfunction due to EDS as part of a global assessment of sleep quality. ${ }^{32}$ In addition to scales that evaluate EDS, the Swiss Narcolepsy Scale (SNS) is a 5-item, self-report scale that assesses for symptoms of narcolepsy with cataplexy. The SNS has a reported 96\% sensitivity and 98\% specificity for NT1 (narcolepsy with cataplexy). ${ }^{33}$

\section{Objective Testing}

If narcolepsy is suspected following the clinical assessment, objective testing is the next step to confirming a diagnosis. The International Classification of Sleep Disorders - Third Edition (ICSD-3) has classified NT1 and NT2. 'Both present with symptoms of EDS, sleep paralysis, and hypnagogic hallucinations, and the supportive criteria for objective testing is the same. An overnight PSG followed by next-day MSLT is the standard of care 
for objective testing. ${ }^{1,34}$ Specific parameters that meet the diagnostic criteria for narcolepsy include a mean sleep latency of less than or equal to eight minutes and two or more SOREMs on the MSLT. Alternatively, a SOREM on the preceding night's PSG should be counted in addition to any SOREM on the MSLT. ${ }^{1}$ The PSG must be performed on the night immediately preceding MSLT to rule out other sleep disorders and evaluate for sleep disruptions that could influence the result of the MSLT. A sleep diary and/or actigraphy should be done 1-2 weeks prior to the PSG/MSLT to ensure that the sleep studies are completed during the patient's usual sleep times. ${ }^{34,35}$ Additional instructions prior to MSLT are presented in Table 1.

MSLT measures the physiological tendency to fall asleep under standardized conditions. The MSLT begins 1.5 to $3 \mathrm{hrs}$ after the PSG and consists of five nap opportunities at $2 \mathrm{hr}$ intervals. The patient is allowed up to 20 mins to fall asleep and then up to 15 mins to enter REM sleep. ${ }^{34}$ Sleep latency, defined as the time from lights out to the first epoch of any stage of sleep, is recorded for each nap. Sleep latency is considered an indicator of the level of sleepiness, and decreased mean sleep latency on the MSLT is associated with sleep disorders that cause EDS, including narcolepsy and OSA. ${ }^{34}$ The presence of SOREMs is also evaluated during each nap, defined as the first epoch of REM sleep that occurs during the nap. Narcolepsy is a disorder of REM sleep, and these patients typically enter REM sleep earlier than expected, which is identified as a SOREM during the nap. $^{34}$
The MSLT must be performed under standardized conditions to maintain the validity of the results. The testing environment should be conducive to sleep and comfortable for the patient, and the test should be performed using a defined protocol. ${ }^{34}$ Additionally, patients should not be taking any drugs that could affect sleep or cause sleepiness, such as stimulants, central nervous system depressants, or REM-suppressing medications. These medications should ideally be stopped two weeks prior to the MSLT, depending on the half-life of the drug, and confirmed with a urine drug screen prior to the MSLT. ${ }^{1,34}$ Despite these recommendations, it is challenging to ensure an adequate washout period of each drug. This can be especially difficult in patients who are taking antidepressant medications and the nature of their psychiatric illness limits the safe taper of these medications. The diagnosis of narcolepsy by PSG/MSLT in such patients may be missed due to the REM-suppressing effects of these drugs. However, it can be difficult to wean off these medications in clinical practice and the interpretation should be done with this limitation in mind.

Polysomnography is the standard diagnostic test for $\mathrm{OSA}^{36}$ which can coexist with narcolepsy. ${ }^{4}$ OSA can be an independent cause of EDS, decreased sleep latency, and SOREMs, and should be treated prior to establishing a narcolepsy diagnosis. ${ }^{34,35}$ A large retrospective study showed that male sex and extent of oxygen desaturation were some of the factors associated with SOREMs in OSA. $^{23}$ If OSA is identified on the PSG, continuous positive airway pressure (CPAP) is instituted. Re-evaluation of EDS by the Epworth Sleepiness Scale is done after

Table I Instructions For Multiple Sleep Latency Testing

\begin{tabular}{|l|l|}
\hline Before The MSLT & During The MSLT \\
\hline Sleep logs/diary/actigraphy for at least one week & $\begin{array}{l}\text { Maintain dark and quiet environment with room } \\
\text { temperature set to patient's comfort }\end{array}$ \\
\hline $\begin{array}{l}\text { Medication review and "washout" if indicated. Stimulant, stimulant-like medications, and } \\
\text { REM-suppressing medications stopped two weeks prior. Other usual medications } \\
\text { discussed with provider to ensure that stimulating or sedating effects of medications are } \\
\text { minimized. }\end{array}$ & $\begin{array}{l}\text { Avoid vigorous physical activity and stop any simulating } \\
\text { activity I5 mins prior to each nap }\end{array}$ \\
\hline Urine drug screen & Abstain from caffeine and alcohol \\
\hline & $\begin{array}{l}\text { Avoid lying down or falling asleep between naps } \\
\text { Avoid bright lights and direct sunlight }\end{array}$ \\
\hline & Abstain from smoking 30 mins prior to each nap \\
\hline
\end{tabular}

Note: Data from Littner et al. ${ }^{34}$ 
adequate compliance ( $>4$ hrs of nightly use for $>70 \%$ of nights) is shown on the CPAP device for a stable duration of four weeks. Additionally, the absence of significant mask leak and an adequate CPAP pressure to control the AHI and nocturnal hypoxemia should be confirmed before pursuing alternate causes of EDS. ${ }^{4,37}$ Other causes of EDS need to be ruled out prior to initiation of wake promoting drugs versus MSLT including suboptimal objective adherence, poor sleep hygiene, insufficient sleep, depression and/or restless legs syndrome. ${ }^{38}$ If after careful consideration it is determined that the patient should undergo MSLT, the preceding PSG is performed with the patient's CPAP device. The use of CPAP is necessary because untreated OSA can cause SOREMs. ${ }^{9,23}$

OSA and narcolepsy both present with EDS, and the severity of EDS in patients with both conditions versus just narcolepsy has not been shown to be significantly different. ${ }^{4,37}$ Narcolepsy can be missed, especially if cataplexy is not identified at the initial presentation, which leads to treatment delays. Therefore, diagnostic testing for narcolepsy should be considered in patients with residual EDS despite CPAP therapy. ${ }^{4,37}$

EDS can also be objectively evaluated after treatment initiation with the maintenance of wakefulness test (MWT). Whereas the MSLT measures the tendency to fall asleep, the MWT measures the ability to stay awake. ${ }^{34}$ The MWT must be performed using a standardized protocol. A preceding PSG is optional; however, optimal sleep and daytime alertness must be confirmed prior to the test, generally by sleep logs or self-report. The test begins 1.5 to $3 \mathrm{hrs}$ after the typical wake time and consists of four trials at $2 \mathrm{hr}$ intervals, during which the patient is seated in a room with minimal light and instructed to stay awake. Each trial ends after 40 mins of wakefulness or if sleep onset occurs during the trial, whichever comes first. Sleep latency is recorded for each trial, and the mean sleep latency is interpreted in the context of the clinical situation. ${ }^{34}$ Clinical application of the MWT lies in the change in mean sleep latency that occurs in response to treatment for a disorder that is known to cause EDS, such as narcolepsy or OSA. This may be especially significant if the patient has an occupation that involves driving. ${ }^{34}$

As outlined above, actigraphy or sleep logs are needed prior to the PSG/MSLT to ensure the test accuracy. However, challenges can arise because actigraphy is not universally available and sleep logs are a very subjective measure. Sleep deprivation or circadian rhythm disorder could therefore be missed during the clinical evaluation, and the patient could be falsely labeled as narcoleptic due to the effects of sleep deprivation/disruption on the PSG and MSLT.

Measurement of CSF hypocretin levels would be useful in a situation when the MSLT results are believed to be falsely negative, particularly when the patient is taking REM-suppressing medications. This test is now commercially available at the Mayo Clinic, Rochester, MN, USA. ${ }^{39}$ However, this test is only useful in diagnosing NT1 and not NT2. One may argue that clinical judgment should be used to guide the management of narcolepsy rather than relying solely on the objective measures of PSG/MSLT. A trial of wake-promoting drugs such as modafinil or sodium oxybate for a short duration with close clinical follow-up may be a consideration. Additionally, patients with narcolepsy could be misdiagnosed and treated as attention deficit hyperactivity disorder (ADHD) due to overlap in the symptomatology. Therefore, screening patients with ADHD for hypersomnia should be encouraged, especially in children. ${ }^{40,41}$

\section{Laboratory Evaluation}

As an alternative to MSLT, NT1 could be diagnosed solely on reduced CSF hypocretin levels in the presence of EDS. Measurement of CSF hypocretin levels by radioimmunoassay (RIA) has been included in the recent ICSD-3 definition of NT1. ${ }^{1}$ Levels of hypocretin $\leq 110 \mathrm{pg} / \mathrm{mL}$ are highly specific for the diagnosis of NT1. ${ }^{42}$ However, RIA lacks accuracy because it cross-reacts with various matrix constituents, which induces variability between batches. Low levels of hypocretin can also be found in patients with traumatic brain injury; therefore, interpretation should include the clinical context. ${ }^{43}$ A recent study compared hypocretin/orexin A levels measured by RIA (Phoenix Pharmaceuticals, Burlingame, CA, USA) to ELISA (Wako Pure Chemical Industries, Osaka, Japan) and found reliable results in that the measurements were not equivalent (orexin A levels were much lower when measured by EILSA versus RIA) ${ }^{44}$ CSF hypocretin testing has limited commercial availability, which limits its widespread use. However, per the ICSD-3 definition, patients with low hypocretin levels are diagnosed as NT1 even in the absence of cataplexy. ${ }^{1}$ This is supported by prospective data that show patients with low hypocretin eventually develop cataplexy. ${ }^{45}$

HLA testing may be used to support a diagnosis of narcolepsy, but it is not considered a diagnostic test. ${ }^{1}$ HLA-DQB $1 * 06: 02$ is a genetic marker that is strongly 
associated with NT1 but can also be present in healthy individuals. HLA testing may be a useful first step if CSF hypocretin testing is being considered because the hypocretin level is unlikely to be reduced if the HLA testing is negative. ${ }^{1,46}$ Again, both CSF hypocretin testing and HLA testing should be interpreted within the clinical context. ${ }^{42,46}$

\section{Current Treatments}

\section{Narcolepsy}

\section{Non-Pharmacological Management}

Non-pharmacological therapies are considered to be adjunctive in the management of narcolepsy. Scheduled daytime naps improve alertness and decrease unintended sleep periods. ${ }^{47}$ Patients may take two $15-$ to $20 \mathrm{~min}$ regularly scheduled naps that are well-timed to facilitate optimal alertness when it is most needed during the day. They should also be encouraged to maintain an adequate and consistent nocturnal sleep schedule and practice good sleep hygiene to avoid exacerbation of symptoms that can occur with sleep deprivation. ${ }^{47,48}$ Medications that cause insomnia or sleepiness should be avoided. Additionally, weight loss should be encouraged if patients are overweight or obese. ${ }^{14}$ Weight loss may be especially important if the patient has comorbid OSA.

Social support is an important element in the management of narcolepsy. Narcolepsy can have negative social, occupational, and economic consequences for the patient, partner, and family. ${ }^{49}$ The social and occupational needs of the patient should be evaluated to determine if intervention is needed. Regular follow-up is important to identify supportive resources, monitor treatment response, and provide ongoing education. Safety must always be evaluated, and patients should be counseled to avoid driving or operating heavy machinery at home or at work while sleepy. ${ }^{47}$ Lastly, regular screening for mood changes and hypertension is needed due to the side effects of simulant medications. ${ }^{47,50}$

\section{Pharmacological Management}

To date, there is no cure for narcolepsy. Symptomatic relief is achieved through various medications. Wake-promoting drugs such as modafinil or sodium oxybate are the mainstay of therapy for EDS (Table 2). Additionally, stimulant medications may be used. The main side effects of stimulants are headaches, irritability, and agitation. These effects occur due to sympathetic stimulation and limit usage in certain patients. Caution should be exercised in patients who have uncontrolled hypertension or a previous cardiac history. Approximately one-third of patients develop tolerance, with the need to increase the dosage. Although these medications are effective, due to the potential for addiction and negative side effects, there is a need for newer, non-stimulating wake-promoting agents. ${ }^{51}$ Although abuse potential is a concern, a cross-sectional cohort study found an extremely low frequency of stimulant abuse among narcolepsy patients. ${ }^{52}$

\section{Stimulant Therapy Approved For Narcolepsy And OSA \\ Modafinil}

Modafinil is a benzyhydrylsulfinylacetamide derivative and a non-amphetamine stimulant. It is considered the first-line treatment for EDS by the American Academy of Sleep Medicine (AASM). ${ }^{47}$ The mechanism of action is not fully understood, but it is believed to be related to dopamine reuptake inhibition. ${ }^{51,54}$ It is readily absorbed after oral administration, with maximum plasma concentration occurring within 2 to $4 \mathrm{hrs} .{ }^{54}$ It is metabolized by the liver with renal elimination. The FDA published a maximum dosage of $400 \mathrm{mg}$, but dosages up to $600 \mathrm{mg}$ have been studied with positive results. ${ }^{53}$ The typical prescribed dosage varies from $100 \mathrm{mg}$ to $400 \mathrm{mg}$ administered once or twice per day. ${ }^{51}$ In $50-60 \%$ of adults with narcolepsy, modafinil is sufficient as a monotherapy, though it has no effect on cataplexy. ${ }^{55}$ It has also been shown to improve objective and subjective sleepiness in patients with OSA with refractory sleepiness despite compliant use of CPAP. Additionally, it has been shown to improve behavioral alertness with reduction in functional impairment in OSA patients on CPAP. ${ }^{56}$

\section{Armodafinil}

Armodafinil is the R-enantiomer of modafinil, which acts as a D2 receptor partial agonist. ${ }^{53,57}$ Armodafinil is administered once daily at $100 \mathrm{mg}$ to $250 \mathrm{mg}$ and is FDA-approved for EDS in patients with OSA and narcolepsy., ${ }^{3,57}$ Though the half-lives of modafinil and armodafinil are similar, differences in pharmacokinetics result in the plasma concentration of armodafinil being higher late in the day leading to improved wakefulness throughout the day. ${ }^{58}$

\section{Solriamfetol}

Solriamfetol is a dopamine and norepinephrine reuptake inhibitor that received FDA approval in 2019 for EDS in OSA and narcolepsy. The approval was granted after 
Table 2 Pharmacologic Management For Excessive Daytime Sleepiness

\begin{tabular}{|c|c|c|c|c|c|c|}
\hline Medication & Mechanism Of Action & $\begin{array}{l}\text { Half- } \\
\text { Life }\end{array}$ & Indication & Dosage & Side Effects & Ref \\
\hline Modafinil & $\begin{array}{l}\text { Not fully understood; Inhibits } \\
\text { dopamine reuptake }\end{array}$ & $15 \mathrm{hrs}$ & $\begin{array}{l}\text { Improve } \\
\text { wakefulness in } \\
\text { patients with EDS }\end{array}$ & $\begin{array}{l}100 \mathrm{mg}-400 \\
\mathrm{mg} \text { daily; up } \\
\text { to } 600 \mathrm{mg} \\
\text { (off-label) }\end{array}$ & $\begin{array}{l}\text { Headache } \\
\text { Nausea } \\
\text { Nervousness } \\
\text { Anxiety } \\
\text { Insomnia }\end{array}$ & 80 \\
\hline $\begin{array}{l}\text { Armodafinil } \\
\text { (R-enantiomer of } \\
\text { Modafinil) }\end{array}$ & $\begin{array}{l}\text { Not fully understood; Inhibits } \\
\text { dopamine reuptake }\end{array}$ & $15 \mathrm{hrs}$ & $\begin{array}{l}\text { Improve } \\
\text { wakefulness in } \\
\text { patients with EDS }\end{array}$ & $\begin{array}{l}\text { I } 50 \text { mg-250 } \\
\text { mg daily }\end{array}$ & $\begin{array}{l}\text { Headache } \\
\text { Nausea } \\
\text { Dizziness } \\
\text { Insomnia }\end{array}$ & 81 \\
\hline Methylphenidate & $\begin{array}{l}\text { CNS stimulant; Inhibits reuptake } \\
\text { and increases release of dopamine } \\
\text { and norepinephrine }\end{array}$ & $3.5 \mathrm{hrs}$ & $\begin{array}{l}\text { Improve } \\
\text { wakefulness in } \\
\text { patients with EDS }\end{array}$ & $\begin{array}{l}10 \text { mg-60 } \\
\text { mg daily in } \\
2-3 \text { divided } \\
\text { doses }\end{array}$ & $\begin{array}{l}\text { Nervousness } \\
\text { Insomnia } \\
\text { Anorexia } \\
\text { Nausea } \\
\text { Headache } \\
\text { Dizziness } \\
\text { Palpitations } \\
\text { Hypertension } \\
\text { Weight Loss } \\
\text { Increased HR and BP } \\
\text { Psychosis }\end{array}$ & 61 \\
\hline $\begin{array}{l}\text { Dextroamphetamines } \\
\text { sulfate }\end{array}$ & $\begin{array}{l}\text { CNS stimulant; Inhibits reuptake } \\
\text { and increases release of dopamine } \\
\text { and norepinephrine }\end{array}$ & II hrs & $\begin{array}{l}\text { Improve } \\
\text { wakefulness in } \\
\text { patients with EDS }\end{array}$ & $\begin{array}{l}5 \mathrm{mg}-60 \mathrm{mg} \\
\text { daily }\end{array}$ & $\begin{array}{l}\text { Insomnia } \\
\text { Anorexia } \\
\text { Headache } \\
\text { Xerostomia } \\
\text { Emotional Lability } \\
\text { Dizziness } \\
\text { Palpitations } \\
\text { Increased HR and BP } \\
\text { Psychosis }\end{array}$ & 82 \\
\hline Solriamfetol & $\begin{array}{l}\text { Inhibits reuptake of dopamine and } \\
\text { norepinephrine }\end{array}$ & $7 \mathrm{hrs}$ & $\begin{array}{l}\text { Improve } \\
\text { wakefulness in } \\
\text { patients with EDS }\end{array}$ & $\begin{array}{l}75 \mathrm{mg}-150 \\
\mathrm{mg} \text { daily }\end{array}$ & $\begin{array}{l}\text { Headache } \\
\text { Nausea } \\
\text { Insomnia } \\
\text { Anxiety } \\
\text { Decreased Appetite }\end{array}$ & 60 \\
\hline Sodium Oxybate & $\begin{array}{l}\text { Not fully understood; CNS } \\
\text { depressant, possibly through binding } \\
\text { to GABA-B receptors; MOA for } \\
\text { effect on cataplexy unknown }\end{array}$ & $\begin{array}{l}0.5 \text { to } \\
\mathrm{I} \mathrm{hr}\end{array}$ & $\begin{array}{l}\text { Improve } \\
\text { wakefulness and } \\
\text { decrease cataplexy } \\
\text { in patients with } \\
\text { narcolepsy }\end{array}$ & $\begin{array}{l}4.5 \text { grams-9 } \\
\text { grams } \\
\text { nightly in } 2 \\
\text { divided } \\
\text { doses }\end{array}$ & $\begin{array}{l}\text { Headache } \\
\text { Nausea } \\
\text { Dizziness } \\
\text { Somnolence } \\
\text { Enuresis } \\
\text { Tremor } \\
\text { Sleepwalking } \\
\text { Confusion } \\
\text { Depressive Symptoms }\end{array}$ & 83 \\
\hline Pitolisant & H3 histamine receptor antagonist & $\begin{array}{l}10- \\
12 \mathrm{hrs}\end{array}$ & $\begin{array}{l}\text { Improve } \\
\text { wakefulness in } \\
\text { patients with } \\
\text { narcolepsy }\end{array}$ & $\begin{array}{l}9 \mathrm{mg}-36 \mathrm{mg} \\
\text { daily }\end{array}$ & $\begin{array}{l}\text { Headache } \\
\text { Insomnia } \\
\text { Nausea } \\
\text { Anxiety } \\
\text { Irritability }\end{array}$ & 63 \\
\hline
\end{tabular}


publication of the results from the TONES studies (Treatment of Obstructive Sleep Apnea and Narcolepsy Excessive Sleepiness). ${ }^{59,60}$ Solriamfetol is approved in 75 $\mathrm{mg}$ and $150 \mathrm{mg}$ dosages for narcolepsy and $37.5 \mathrm{mg}, 75$ $\mathrm{mg}$, and $150 \mathrm{mg}$ dosages for OSA. The most common adverse effects are headaches, anxiety, decreased appetite, and nausea.

\section{Other Stimulant Therapies For Narcolepsy Methylphenidate}

Methylphenidate is a derivative of amphetamines. It is a non-competitive dopamine reuptake blocker with some inhibiting action on serotonin-noradrenaline reuptake. In patients with narcolepsy, methylphenidate improves objective and subjective sleepiness but shows mixed results on performance tests. ${ }^{61}$ The starting dose is $10 \mathrm{mg}$ per day, with a recommended maximum dose of $60 \mathrm{mg}$ per day. Side effects include nausea, reduced appetite, headache, insomnia, and psychosis. Due to its adverse reactions and abuse potential, it is a second-line treatment or add-on therapy for more stressful situations. ${ }^{62}$

\section{Dextroamphetamine Sulfate (R-Amphetamine Sulfate Enantiomer)}

Dextroamphetamine is a competitive dopamine transporter blocker and is considered third-line therapy due to abuse potential.

\section{Pitolisant}

Pitolisant is the first antagonist of the histamine H3 autoreceptor and increases histamine release in the hypothalamus and cortex. ${ }^{62}$ In contrast to the $\mathrm{H} 1$ receptor, H3 receptors are saturated in the CNS and therefore may not cause the same side effects that have limited the use of $\mathrm{H} 1$ receptor stimulators. In a double-blinded study in five European countries, pitolisant was found to be better tolerated than modafinil. ${ }^{63}$ However, its efficacy is comparable to modafinil. ${ }^{51}$ The dosage ranges from 9 to $36 \mathrm{mg}$ daily, and the half-life is about 10-12 hrs. Side effects include headache, insomnia, nausea, and anxiety. Pitolisant has been available in Europe for some time and received FDA approval in the United States for EDS in narcolepsy in 2019.

\section{Sodium Oxybate $\left(\right.$ Xyrem $\left.^{\circledR}\right)$}

Sodium oxybate is the sodium salt of g-hydroxybutyrate and considered a standard therapy for EDS with or without cataplexy by the AASM. ${ }^{47}$ It has been shown to decrease attacks of cataplexy, increase sleep latency, and reduce sleep attacks. ${ }^{64}$ The mechanism of action remains incompletely understood, but it is partially believed to act on the GABA-B receptors. ${ }^{51,62}$

Sodium oxybate has a very short half-life; two doses are required nightly. The dosing starts with 2.25 grams twice per night and is titrated up according to the patient's symptoms. The maximum recommended dose is 4.5 grams per dose with two doses per night ( 9 grams per night). The effectiveness of the medication is gradual and time-dependent, with symptom control achieved in 1 month or more. The most frequent side effects are nausea, dizziness, anxiety, and confusion, and the more disabling are enuresis, sleep walking, and mood disturbance. ${ }^{51,62}$ The combination of Modafinil and sodium oxybate may have an additive effect on EDS. ${ }^{65} \mathrm{~A}$ clinical trial is currently underway to assess the efficacy and safety of a once-nightly formulation of sodium oxybate. ${ }^{66}$ REST-ON is a double-blind, randomized, placebo-controlled study of 264 patients to assess the efficacy and safety of a once-nightly formulation of sodium oxybate for the treatment of EDS and cataplexy in patients with narcolepsy. ${ }^{66}$

Sodium oxybate carries a black box warning for abuse and is only dispensed by a central pharmacy per FDA guidelines. Caution is advised for patients with an existing history of depression or untreated sleep apnea. Given that sodium oxybate is a sedating medication, there is a strong warning against taking other sedating medications concurrently due to the risk of respiratory depression. The risk of rebound cataplexy or status cataplecticus is low with withdrawal or disruption of the medication. ${ }^{67}$

\section{Cardiovascular Risk Assessment Prior To Initiation Of Stimulants}

A large retrospective study showed no evidence of increased serious cardiovascular events in patients with ADHD aged 2 to 24 years receiving stimulant medicaitons. ${ }^{68}$ Similar results were seen in another retrospective cohort study in patients with ADHD aged 25 to 64 years. ${ }^{69}$ Based on the aforementioned trials, the FDA concluded that there was no strong association between ADHD pharmacotherapy and adverse cardiovascular events. ${ }^{70}$ Nonetheless, patients should be cautioned about potential changes in heart rate and blood pressure. In general, stimulants should be avoided in patients with cardiovascular disease; if needed, they should be prescribed in consultation with a cardiologist. The American Academy of Pediatrics, American Heart Association, and American 
College of Cardiology recommend a cardiovascular evaluation (history, family history, and examination) in children prior to the initiation of stimulants. ${ }^{71}$

\section{Clinical Dilemma}

Clinicians are faced with challenging questions because studies of stimulant medications and cardiovascular risk did not include patients above 65 years; thus, the effect of pre-existing cardiac conditions in the elderly population is unclear. These studies are also confounded by healthy user bias, which limits generalizability. There is a need for further research on use of stimulants in the elderly population, especially in patients with OSA on CPAP with residual daytime sleepiness.

\section{Excessive Daytime Sleepiness In OSA}

CPAP has been shown to reduce daytime sleepiness and therefore is considered the gold standard for treating patients with OSA. ${ }^{72}$ The efficacy of CPAP therapy depends significantly on the compliance and hours of usage. A multicenter, quasi-experimental study in patients with severe sleep apnea showed that at least $4 \mathrm{hrs}$, $6 \mathrm{hrs}$, and $7.5 \mathrm{hrs}$ of nightly CPAP usage were needed to show an improvement in the ESS score, MSLT, and Functional Outcomes of Sleep Questionnaire, respectively. The authors concluded that more hours of CPAP use is associated with greater improvement in sleepiness. However, there is variation in the amount of CPAP use required to normalize sleepiness, so nightly use recommendations may be individualized and considered in terms of desired treatment outcomes. ${ }^{73}$ If there is persistence of residual daytime sleepiness after adequate CPAP use, clinical assessment as mentioned above should be performed. If no modifiable factors are identified and the patient is compliant with CPAP, MSLT could be considered. Alternatively, a trial of stimulant therapy may be considered.

\section{Clinical Challenge}

Meticulous stepwise screening for comorbidities contributing to EDS in OSA patients is warranted. Achieving the above-mentioned CPAP usage parameters is a significant challenge in the management of EDS. As a result, patients are prematurely started on stimulant therapy for clinical improvement and patient satisfaction, potentially exposing them to adverse effects.

\section{Co-Management Of OSA In Narcolepsy} Although sleepiness improves with CPAP therapy in patients with comorbid narcolepsy and OSA, narcolepsy- related EDS is not expected to respond to CPAP. Therefore, the mainstay of therapy for narcolepsy should be medications. CPAP in narcoleptics with OSA should remain a second-line, adjunctive therapy to standard pharmacological treatments. ${ }^{37}$

\section{Pediatric Population}

EDS is required for the diagnosis of narcolepsy in the pediatric population. In younger children, EDS may be vague and present as behavior problems or concentration difficulties. ${ }^{74}$ Treatment of narcolepsy in the pediatric population is similar to the treatment in adults. ${ }^{51}$ Sodium oxybate has recently been approved for use in children ages 7 and older and is the only FDA approved medication for the treatment of EDS and cataplexy in the pediatric population. The dosing for sodium oxybate in children is weight based, and the most common side effects include enuresis, nausea/vomiting, headache, decreased weight/ appetite and dizziness. ${ }^{75}$ Children with both narcolepsy and mild to moderate OSA have shown improvement in daytime sleepiness following adenotonsillectomy. ${ }^{76}$

\section{Future Trends}

Availability of CSF hypocretin testing is forthcoming in the United States, but the cost of testing and performing the lumbar puncture is unknown and there are risks associated with the procedure itself. To date, there is no cure for narcolepsy, and management focuses on symptomatic relief with medications. Orexin supplementation is a novel therapy that has a potential role in treating the disease. Various modalities have been proposed, including orexin agonists, gene therapy, and cell transplantation. Recent experiments in mice showed that central administration of orexin in orexin-cell-ablated mice improved wakefulness and reduced cataplexy. ${ }^{77}$ Other studies showed amelioration of narcolepsy symptoms with peripherally administered YNT-185 (non-peptide selective orexin type-2 receptor agonist) ${ }^{78}$ and TAK-925 (orexin 2 receptor selective agonist) ${ }^{79}$ in mice models, providing further proof of concept. Human studies with oral formulations of orexin agonists are in the beginning stages.

\section{Clinical Case I}

30-year-old male with no significant past medical history came to the sleep clinic for evaluation of snoring. His wife was having difficulty sharing the bedroom with him due to loud snoring. His Epworth Sleepiness Scale (ESS) score was $15 / 24$. Additionally, he reported dry mouth and morning headaches upon waking up. Infrequently, he felt 
"trapped in his body" due to the inability to move his body while trying to initiate sleep. He had good sleep hygiene with an average total sleep time of 7.5 hrs. Physical exam revealed BMI of 36, Modified Mallampati score of III, macroglossia, and neck circumference of 17 inches. The rest of the exam was unremarkable, and the patient was on no medications. The patient underwent attended polysomnography (PSG) in the sleep laboratory. The sleep architecture was normal, and the apnea hypopnea index (AHI) was 20/hour. He was titrated to CPAP of $12 \mathrm{~cm} \mathrm{H}_{2} \mathrm{O}$. He returned for his compliance visit in 3 months and felt more refreshed but still sleepy. The download from the CPAP showed $80 \%$ compliance ( $>4$ hrs usage) with minimal leaks and residual AHI of $0.1 / \mathrm{hr}$. His ESS score was 12/24. In the following clinic visit, the patient did not feel any different and was still sleepy despite $100 \%$ compliance on his CPAP machine. On further questioning, he still had the feeling of inability to move his body while initiating sleep but denied feeling weak with strong emotions. He also endorsed occasional hypnogogic hallucinations. The patient underwent PSG with the CPAP of $12 \mathrm{H}_{2} \mathrm{O}$, followed by MSLT. The AHI on the PSG with CPAP was 1/ hr. MSLT showed 2 SOREMs with mean sleep onset latency of 6 mins. On retrospective review, the first PSG also revealed a REM sleep onset latency of 15 mins. The patient was diagnosed with OSA and narcolepsy and responded to modafinil. This case highlights the fact that narcolepsy could be a missed diagnosis because the signs and symptoms of OSA and narcolepsy may have significant overlap. Note: This case is a mock case used to highlight points raised in the review.

\section{Clinical Case 2}

25-year-old female with a previous diagnosis of NT1 presented with worsening EDS. She was previously well controlled on modafinil $100 \mathrm{mg}$ twice daily. Her cataplexy episodes had already reduced in frequency and she did not require any specific treatment for it. Recently, she started working in the corporate sector and living independently. In the interim, she was diagnosed with depression and started on fluoxetine. Since then, her EDS had worsened. She also gained 10 pounds in the past 2 years. Her sleep routine was consistent, with 7 to $8 \mathrm{hrs}$ of sleep, though she was unable to nap now. Her caffeine intake had also increased, and her ESS during the clinic visit was 14/24 which was up from 9/24 one year ago. On further questioning, the patient had been told that she started snoring. On physical exam, her BMI was 30 and her Modified
Mallampati score was III with $2+$ tonsils. The rest of the exam was unremarkable. The patient was screened for OSA with a PSG. She was diagnosed with moderate OSA and was initiated on CPAP while she continued on modafinil. After 3 months of CPAP usage, she returned to clinic for re-evaluation. She had excellent compliance with $>4 \mathrm{hrs}$ usage of $90 \%$ and residual AHI of $1 / \mathrm{hr}$. Her EDS had improved and her ESS was 8/24. This case demonstrates that other causes of EDS should be re-evaluated in patients presenting with worsening of the previously wellcontrolled symptoms of narcolepsy. Note: This case is a mock case used to highlight points raised in the review.

\section{Disclosure}

This work did not receive any specific grant from funding agencies in the public, commercial, or not-for-profit sectors. The authors report no conflicts of interest in this work.

\section{References}

1. American Academy of Sleep Medicine. International Classification of Sleep Disorders. 3rd ed. Darien, IL: Author; 2014.

2. Jaussent I, Morin CM, Ivers H, Dauvilliers Y. Incidence, worsening and risk factors of daytime sleepiness in a population-based 5-year longitudinal study. Sci Rep. 2017;7(1):1372. doi:10.1038/s41598017-01547-0

3. Schwartz JR, Khan A, McCall WV, Weintraub J, Tiller J. Tolerability and efficacy of armodafinil in naive patients with excessive sleepiness associated with obstructive sleep apnea, shift work disorder, or narcolepsy: a 12-month, open-label, flexible-dose study with an extension period. J Clin Sleep Med. 2010;6(5):450-457.

4. Sansa G, Iranzo A, Santamaria J. Obstructive sleep apnea in narcolepsy. Sleep Med. 2010;11(1):93-95. doi:10.1016/j.sleep.2009.02.009

5. Chapman JL, Serinel Y, Marshall NS, Grunstrin RR. Residual daytime sleepiness in obstructive sleep apnea after continuous positive airway pressure optimization: causes and management. Sleep Med Clin. 2016;11(3):353-363. doi:10.1016/j.jsmc.2016.05.005

6. Senaratna CV, Perret JL, Lodge CJ, et al. Prevalence of obstructive sleep apnea in the general population: a systematic review. Sleep Med Rev. 2017;34:70-81. doi:10.1016/j.smrv.2016.07.002

7. Goldbart A, Peppard P, Finn L, et al. Narcolepsy and predictors of positive MSLTs in the Wisconsin Sleep Cohort. Sleep. 2014;37 (6):1043-1051. doi:10.5665/sleep. 3758

8. Schuld A, Hebebrand J, Geller F, Pollmacher T. Increased body-mass index in patients with narcolepsy. Lancet. 2000;355(9211):12741275. doi:10.1016/S0140-6736(05)74704-8

9. Singh M, Drake CL, Roth T. The prevalence of multiple sleep-onset REM periods in a population-based sample. Sleep. 2006;29(7):890895. doi:10.1093/sleep/29.7.890

10. de Lecea L, Kilduff TS, Peyron C, et al. The hypocretins: hypothalamus-specific peptieds with neuroexcitatory activity. Proc Natl Acad Sci USA. 1998;95(1):322-327. doi:10.1073/pnas.95.1.322

11. Sakurai T, Amemiya A, Ishii M, et al. Orexins and orexin receptors: a family of hypothalamic neuropeptides and $\mathrm{g}$ protein-coupled receptors that regulate feeding behavior. Cell. 1998;92(4):573-585. doi:10.1016/s0092-8674(00)80949-6

12. Kornum BR, Knudsen S, Ollila HM, et al. Narcolepsy. Nat Rev Dis Primers. 2017;3:16100. doi:10.1038/nrdp.2016.100 
13. Mignot E, Lin L, Rogers W, et al. Complex HLA-DR and -DQ interactions confer risk of narcolepsy-cataplexy in three ethnic groups. Am J Hum Genet. 2001;68(3):686-699. doi:10.1086/318799

14. Heier MS, Jansson TS, Gautvik KM. Cerebrospinal fluid hypocretin 1 deficiency, overweight, and metabolic dysregulation in patients with narcolepsy. J Clin Sleep Med. 2011;7(6):653-658. doi:10.5664/ jcsm. 1474

15. Luca G, Haba-Rubio J, Dauvilliers Y, et al. Clinical, polysomnographic and genome-wide association analyses of narcolepsy with cataplexy: a European Narcolepsy Network study. J Sleep Res. 2013;22(5):482-495. doi:10.1111/jsr.12044

16. Fortuyn HA, Swinkels S, Buitelaar J, et al. High prevalence of eating disorders in narcolepsy with cataplexy: a case-control study. Sleep. 2008;31(3):335-341. doi:10.1093/sleep/31.3.335

17. van Holst RJ, van der Cruijsen L, van Mierlo P, et al. Aberrant food choices after satiation in human orexin-deficient narcolepsy type 1 . Sleep. 2016;39(11):1951-1959. doi:10.5665/sleep.6222

18. He K, Kapur VK. Sleep-disordered breathing and excessive daytime sleepiness. Sleep Med Clin. 2017;12(3):369-382. doi:10.1016/j. jsmc.2017.03.010

19. Mediano O, Barcelo A, de la Pena M, Gozal D, Agusti A, Barbe F. Daytime sleepiness and polysomnographic variables in sleep apnoea patients. Eur Respir J. 2007;30(1):110-113. doi:10.1183/ 09031936.00009506

20. Garbarino S, Scoditti E, Lanteri P, Conte L, Magnavita N, Toraldo DM. Obstructive sleep apnea with our without excessive daytime sleepiness: clinical and experimental data-driven phenotyping. Front Neurol. 2018;9:505. doi:10.3389/fneur.2018.00505

21. Veasey SC, Davis CW, Fenik P, et al. Long-term intermittent hypoxia in mice: protracted hypersomnolence with oxidative injury to sleepwake brain regions. Sleep. 2004;27(2):194-201. doi:10.1093/sleep/ 27.2.194

22. Zhu Y, Fenik P, Zhan G, et al. Selective loss of catecholaminergic wake active neurons in a murine sleep apnea model. $J$ Neurosci. 2007;27(37):10060-10071. doi:10.1523/JNEUROSCI.0857-07.2007

23. Chervin RD, Aldrich MS. Sleep onset REM periods during multiple sleep latency tests in patients evaluated for sleep apnea. Am J Respir Crit Care Med. 2000;161(2 Pt 1):426-431. doi:10.1164/ ajrccm.161.2.9905071

24. Lombardi C, Parati G, Cortelli P, et al. Daytime sleepiness and neural cardiac modulation in sleep-related breathing disorders. J Sleep Res. 2008;17(3):263-270. doi:10.1111/j.1365-2869.2008.00659.x

25. Castiglioni P, Lombardi C, Di Rienzo M, et al. What are the causes of excessive daytime sleepiness in patients with sleep-disordered breathing? Eur Respir J. 2008;32(2):526-527. doi:10.1183/09031936.00043308

26. Panossian LA, Veasey SC. Daytime sleepiness in obesity: mechanisms beyond obstructive sleep apnea - a review. Sleep. 2012;35 (5):605-615. doi:10.5665/sleep. 1812

27. Johns MW. A new method for measuring daytime sleepiness: the Epworth sleepiness scale. Sleep. 1991;14(6):540-545. doi:10.1093/ sleep/14.6.540

28. Johns M, Hocking B. Daytime sleepiness and sleep habits of Australian workers. Sleep. 1997;20(10):844-849. doi:10.1093/sleep/20.10.844

29. Janssen KC, Phillipson S, O'Connor J, Johns MW. Validation of the epworth sleepiness scale for children and adolescents using rasch analysis. Sleep Med. 2017;33:30-35. doi:10.1016/j.sleep.2017.01.014

30. Hoddes E, Zarcone V, Smythe H, Phillips R, Dement WC. Quantification of sleepiness: a new approach. Psychophysiology. 1973;10(4):431-436. doi:10.1111/j.1469-8986.1973.tb00801.x

31. Kaida K, Takahashi M, Akerstedt T, et al. Validation of the Karolinska sleepiness scale against performance and EEG variables. Clin Neurophysiol. 2006;117(7):1574-1581. doi:10.1016/j.clinph.2006.03.011

32. Buysse DJ, Reynolds CF 3rd, Monk TH, Berman SR, Kupfer DJ. The Pittsburgh sleep quality index: a new instrument for psychiatric practice and research. Psychiatry Res. 1989;28(2):193-213. doi:10.1016/0165-1781(89)90047-4
33. Sturzenegger C, Bassetti CL. The clinical spectrum of narcolepsy with cataplexy: a reappraisal. J Sleep Res. 2004;13(4):395-406. doi:10.1111/j.1365-2869.2004.00422.x

34. Littner MR, Kushida C, Wise M, et al. Practice parameters for clinical use of the multiple sleep latency test and the maintenance of wakefulness test. Sleep. 2005;28(1):113-121. doi:10.1093/sleep/28.1.113

35. Kushida CA, Littner MR, Morgenthaler T, et al. Practice parameters for the indications for polysomnography and related procedures: an update for 2005. Sleep. 2005;28(4):499-521. doi:10.1093/sleep/ 28.4.499

36. Kapur VK, Auckley DH, Chowdhuri S, et al. Clinical practice guideline for diagnostic testing for adult obstructive sleep apnea: an American academy of sleep medicine clinical practice guideline. $J$ Clin Sleep Med. 2017;13(3):479-504. doi:10.5664/jcsm.6506

37. Pataka AD, Frangulyan RR, Mackay TW, Douglas NJ, Riha RL. Narcolepsy and sleep-disordered breathing. Eur J Neurol. 2012;19 (5):696-702. doi:10.1111/j.1468-1331.2011.03610.x

38. Morgenthaler TI, Kapen S, Lee-Chiong T, et al. Practice parameters for the medical therapy of obstructive sleep apnea. Sleep. 2006;29 (8):1031-1035

39. Mayo Clinic Laboratories. ORXNA: orexin-A/hypocretin-1, spinal fluid. 2019. Available from: https://www.mayocliniclabs.com/test-cat alog/Overview/604230. Accessed August 29, 2019.

40. Morse AM, Sanjeev K. Narcolepsy and psychiatric disorders: comorbidities or shared pathophysiology? Med Sci (Basel). 2018;6(1):16.

41. American Psychiatric Association. Diagnostic and Statistical Manual of Mental Disorders. 5th ed. Arlington, VA: Author; 2013.

42. Mignot E, Lammers GJ, Ripley B, et al. The role of cerebrospinal fluid hypocretin measurement in the diagnosis of narcolepsy and other hypersomnias. Arch Neurol. 2002;59(10):1553-1562. doi:10.1001/archneur.59.10.1553

43. Hirtz C, Vialaret J, Gabelle A, Nowak N, Dauvilliers Y, Lehmann S. From radioimmunoassay to mass spectrometry: a new method to quantify orexin-A (hypocretin-1) in cerebrospinal fluid. Sci Rep. 2016;6:25162. doi:10.1038/srep25162

44. Ono T. Evaluation of commercial RIA and ELISA for measuring CSF orexin-A (hypocretin-1). Sleep. 2017;40(supp11):A247. doi:10.1093/ sleepj/zsx050.667

45. Andlauer O, Moore H, Hong S-C, et al. Predictors of hypocretin (orexin) deficiency in narcolepsy without cataplexy. Sleep. 2012;35 (9):1247-1255F. doi:10.5665/sleep.2080

46. Capittini C, De Silvestri A, Terzaghi M, et al. Correlation between HLA-DQB1*06:02 and narcolepsy with and without cataplexy: approving a safe and sensitive genetic test in four major ethnic groups. A systematic meta-analysis. Sleep Med. 2018;52:150-157. doi:10.1016/j.sleep.2018.08.024

47. Morgenthaler TI, Kapur VK, Brown T, et al. Practice parameters for the treatment of narcolepsy and other hypersomnias of central origin. Sleep. 2007;30(12):1705-1711. doi:10.1093/sleep/30.12.1705

48. Rogers AE, Aldrich MS, Lin X. A comparison of three different sleep schedules for reducing daytime sleepiness in narcolepsy. Sleep. 2001;24(4):385-391. doi:10.1093/sleep/24.4.385

49. Jennum P, Ibsen R, Petersen ER, Knudsen S, Kjellberg J. Health, social, and economic consequences of narcolepsy: a controlled national study evaluating the societal effect on patients and their partners. Sleep Med. 2012;13(8):1086-1093. doi:10.1016/j.sleep.2012.06.006

50. Bosco A, Lopez R, Barateau L, et al. Effect of psychostimulants on blood pressure profile and endothelial function in narcolepsy. Neurology. 2018;90(6):e479-e491. doi:10.1212/WNL.0000000000004911

51. Lammers GJ. Drugs used in narcolepsy and other hypersomnias. Sleep Med Clin. 2018;13(2):183-189. doi:10.1016/j.jsmc.2018.02. 009

52. Mantyh WG, Auger RR, Morgenthaler TI, Silber MH, Moore WR. Examining the frequency of stimulant misuse among patients with primary disorders of hypersomnolence: a retrospective cohort study. $J$ Clin Sleep Med. 2016;12(5):659-662. doi:10.5664/jcsm.5788 
53. Khan Z, Trotti LM. Central disorders of hypersomnolence: focus on the narcolepsies and idiopathic hypersomnia. Chest. 2015;148 (1):262-273. doi:10.1378/chest.14-1304

54. Schwartz JRL. Modafinil in the treatment of excessive sleepiness. Drug Des Devel Ther. 2009;2:71-85.

55. Mitler MM, Harsh J, Hirshkowitz M, Guilleminault C. Long-term efficacy and safety of modafinil (PROVIGIL((R))) for the treatment of excessive daytime sleepiness associated with narcolepsy. Sleep Med. 2000;1(3):231-243.

56. Dinges DF, Weaver TE. Effects of modafinil on sustained attention performance and quality of life in OSA patients with residual sleepiness while being treated with nCPAP. Sleep Med. 2003;4(5):393-402.

57. Kallweit U, Bassetti CL. Pharmacological management of narcolepsy with and without cataplexy. Expert Opin Pharmacother. 2017;18 (8):809-817. doi:10.1080/14656566.2017.1323877

58. Darwish M, Kirby M, Hellriegel ET, Robertson P Jr. Armodafinil and modafinil have substantially different pharmacokinetic profiles despite having the same terminal half-lives: analysis of data from three randomized, single-dose, pharmacokinetic studies. Clin Drug Investig. 2009;29(9):613-623. doi:10.2165/11315280-000000000-00000

59. Schweitzer PK, Rosenberg R, Zammit GK, et al. Solriamfetol for excessive sleepiness in obstructive sleep apnea (TONES 3): a randomized controlled trial. Am J Respir Crit Care Med. 2019;199 (11):1421-1431.

60. Thorpy MJ, Shapiro C, Mayer G, et al. A randomized study of solriamfetol for excessive sleepiness in narcolepsy. Ann Neurol. 2019;85(3):359-370. doi:10.1002/ana.25423

61. Mitler MM, Hajdukovic R, Erman M, Koziol JA. Narcolepsy. J Clin Neurophysiol. 1990;7(1):93-118.

62. Takenoshita S, Nishino S. Pharmacologic management of excessive daytime sleepiness. Sleep Med Clin. 2017;12(3):461-478. doi:10.1016/j.jsmc.2017.03.019

63. Dauvilliers Y, Bassetti C, Lammers GJ, et al. Pitolisant versus placebo or modafinil in patients with narcolepsy: a double-blind, randomised trial. Lancet Neurol. 2013;12(11):1068-1075. doi:10.1016/ S1474-4422(13)70225-4

64. Alshaikh MK, Tricco AC, Tashkandi M, Mamdani M, Straus SE, BaHammam AS. Sodium oxybate for narcolepsy with cataplexy: systematic review and meta-analysis. J Clin Sleep Med. 2012;8 (4):451-458. doi: $10.5664 / \mathrm{jcsm} .2048$

65. Black J, Houghton WC. Sodium oxybate improves excessive daytime sleepiness in narcolepsy. Sleep. 2006;29(7):939-946. doi:10.1093/ sleep/29.7.939

66. Avadel. REST-ON. 2018; http://clinicaltrial.avadel.com/hcp.html. Accessed September 12, 2019.

67. Xyrem ${ }^{\circledR}$ International Study Group. The abrupt cessation of therapeutically administered sodium oxybate (GHB) does not cause withdrawal symptoms. J Toxicol Clin Toxicol. 2003;41(2):131-135.

68. Cooper WO, Habel LA, Sox CM, et al. ADHD drugs and serious cardiovascular events in children and young adults. $N$ Engl J Med. 2011;365(20):1896-1904. doi:10.1056/NEJMoa1110212

69. Habel LA, Cooper WO, Sox CM, et al. ADHD medications and risk of serious cardiovascular events in young and middle-aged adults. Jama. 2011;306(24):2673-2683. doi:10.1001/jama.2011.1830
70. U.S. Food and Drug Administration. FDA drug safety communication: safety review update of medications used to treat attention-deficit/hyperactivity disorder (ADHD) in children and young adults. 2018; http:// www.fda.gov/Drugs/DrugSafety/ucm277770.htm. Accessed September $12,2019$.

71. American Academy of Pediatrics/American Heart. Association clarification of statement on cardiovascular evaluation and monitoring of children and adolescents with heart disease receiving medications for ADHD: May 16, 2008. J Dev Behav Pediatr. 2008;29(4):335.

72. Patil SP, Ayappa IA, Caples SM, Kimoff J, Patel SR, Harrod CG. Treatment of adult obstructive sleep apnea with positive airway pressure: an American academy of sleep medicine clinical practice guideline. J Clin Sleep Med. 2019;15(2):335-343. doi:10.5664/ jesm.7640

73. Weaver TE, Maislin G, Dinges DF, et al. Relationship between hours of CPAP use and achieving normal levels of sleepiness and daily functioning. Sleep. 2007;30(6):711-719. doi:10.1093/sleep/30.6.711

74. Babiker MO, Prasad M. Narcolepsy in children: a diagnostic and management approach. Pediatr Neurol. 2015;52(6):557-565. doi:10.1016/j.pediatrneurol.2015.02.020

75. Plazzi G, Ruoff C, Lecendreux M, et al. Treatment of paediatric narcolepsy with sodium oxybate: a double-blind, placebo-controlled, randomized-withdrawl, multicenter study and open label investigation. Lancet Child Adolesc Health. 2018;2(7):483-494. doi:10.1016/ S2352-4642(18)30133-0

76. Biyani S, Cunningham TD, Baldassari CM. Adenotonsillectomy outcomes in children with sleep apnea and narcolepsy. Int J Pediatr Otorhinolaryngol. 2017;100:62-65. doi:10.1016/j.ijporl.2017.06.018

77. Nepovimova E, Janockova J, Misik J, et al. Orexin supplementation in narcolepsy treatment: a review. Med Res Rev. 2019;39(3):961-975. doi: $10.1002 /$ med.21550

78. Irukayama-Tomobe $\mathrm{Y}$, Ogawa $\mathrm{Y}$, Tominaga $\mathrm{H}$, et al. Nonpeptide orexin type-2 receptor agonist ameliorates narcolepsy-cataplexy symptoms in mouse models. Proc Natl Acad Sci USA. 2017;114 (22):5731-5736. doi:10.1073/pnas.1700499114

79. Kimura H, Ishikawa T, Yukitake H, Suzuki M. An orexin 2 receptorselective agonist, TAK-925, ameliorates narcolepsy-like symptoms and obesity in orexin/ataxin-3 transgenic mice. Sleep. 2019;42 (supp11):A23. doi:10.1093/sleep/zsz067.054

80. Randomized trial of modafinil for the treatment of pathological somnolence in narcolepsy. US modafinil in narcolepsy multicenter study group. Ann Neurol. 1998;43(1):88-97. doi:10.1002/ ana.410430115

81. Harsh JR, Hayduk R, Rosenberg R, et al. The efficacy and safety of armodafinil as treatment for adults with excessive sleepiness associated with narcolepsy. Curr Med Res Opin. 2006;22(4):761-774. doi: $10.1185 / 030079906 \mathrm{X} 100050$

82. Mitler MM, Hajdukovic R, Erman MK. Treatment of narcolepsy with methamphetamine. Sleep. 1993;16(4):306-317.

83. Xyrem ${ }^{\mathbb{B}}$ International Study Group. A double-blind, placebo-controlled study demonstrates sodium oxybate is effective for the treatment of excessive daytime sleepiness in narcolepsy. $J$ Clin Sleep Med. 2005;1(4):391-397.
Nature and Science of Sleep

\section{Publish your work in this journal}

Nature and Science of Sleep is an international, peer-reviewed, open access journal covering all aspects of sleep science and sleep medicine, including the neurophysiology and functions of sleep, the genetics of sleep, sleep and society, biological rhythms, dreaming, sleep disorders and therapy, and strategies to optimize healthy sleep.
The manuscript management system is completely online and includes a very quick and fair peer-review system, which is all easy to use. Visit http://www.dovepress.com/testimonials.php to read real quotes from published authors. 